Research Paper: Immunology

\title{
Discoidin domain receptor 1 promotes Th17 cell migration by activating the RhoA/ROCK/MAPK/ERK signaling pathway
}

\author{
Mohammed-Amine El Azreq ${ }^{1}$, Maleck Kadiri ${ }^{1}$, Marc Boisvert ${ }^{1}$, Nathalie Pagé ${ }^{1}$, \\ Philippe A. Tessier ${ }^{1,2}$ and Fawzi Aoudjit ${ }^{1,2}$ \\ ${ }^{1}$ Axe de Recherche sur les Maladies Infectieuses et Immunitaires, Centre de Recherche du Centre Hospitalier Universitaire \\ de Québec, Québec, QC, Canada \\ ${ }^{2}$ Département de Microbiologie-Immunologie, Faculté de Médecine, Université Laval, Québec, QC, Canada \\ Correspondence to: Fawzi Aoudjit, email: fawzi.aoudjit@crchudequebec.ulaval.ca \\ Keywords: Th17 cells; migration; DDR1; 3D collagen; RhoA/ROCK; Immunology and Microbiology Section, Immune response, Im- \\ munity \\ Received: February 24, $2016 \quad$ Accepted: June 13, $2016 \quad$ Published: July 06, 2016
}

ABSTRACT

Effector $T$ cell migration through the tissue extracellular matrix (ECM) is an important step of the adaptive immune response and in the development of inflammatory diseases. However, the mechanisms involved in this process are still poorly understood. In this study, we addressed the role of a collagen receptor, the discoidin domain receptor 1 (DDR1), in the migration of Th17 cells. We showed that the vast majority of human Th17 cells express DDR1 and that silencing DDR1 or using the blocking recombinant receptor DDR1:Fc significantly reduced their motility and invasion in three-dimensional (3D) collagen. DDR1 promoted Th17 migration by activating RhOA/ROCK and MAPK/ERK signaling pathways. Interestingly, the RhoA/ ROCK signaling module was required for MAPK/ERK activation. Finally, we showed that DDR1 is important for the recruitment of Th17 cells into the mouse dorsal air pouch containing the chemoattractant CCL20. Collectively, our results indicate that DDR1, via the activation of RhOA/ROCK/MAPK/ERK signaling axis, is a key pathway of effector $\mathrm{T}$ cell migration through collagen of perivascular tissues. As such, DDR1 can contribute to the development of Th17-dependent inflammatory diseases.

\section{INTRODUCTION}

T cell migration through ECM in peripheral tissues is critical for the adaptive immune response and in the development of inflammation. To reach their target sites and exert their functions, activated/effector $\mathrm{T}$ cells leave the lymph nodes, enter the circulation, then the perivascular tissues through a process known as transendothelial extravasation $[1,2]$. There, effector $\mathrm{T}$ cells also migrate through the ECM of interstitial tissues in which collagen type I (collagen) is the most abundant matrix $[3,4]$.

The use of 3D collagen models such as collagen gels, which are more relevant physiologically than the 2D models, revealed that cells could use different modes of migration. Cells such as fibroblasts and cancer cells use the mesenchymal-type mode of migration, which is dependent on strong adhesive forces mediated by integrins, stress fiber formation and ECM remodeling by matrix metalloproteinases (MMPs) [5, 6]. However, activated $\mathrm{T}$ cells, dendritic cells and monocytes migrate in 3D collagen and in interstitial tissues using the amoeboid movement, relying on contact guidance and squeezing through existing gaps, independently from integrins and MMPs [7-10]. These studies suggest that additional receptors are likely to stimulate the amoeboid movement of leukocytes in 3D collagen.

Discoidin domain receptors (DDR1 and DDR2) are non-integrin tyrosine kinase transmembrane receptors that bind different types of collagen $[11,12]$. DDR1 is expressed in many epithelial and carcinoma cells and has been associated with cancer cell invasion in 3D collagen mainly through the promotion of MMP production [13]. In this context, it has recently been reported that DDR1 enhances the formation of invadosomes and MMP activity in cancer cells via the small GTPase Cdc42 [14]. DDR1 also stimulates the collective migration of cancer cells via the Gia13 pathway $[15,16]$. In addition to epithelial 
and carcinoma cells, short-term activated human T cells also express DDR1 [17-19] and the blocking recombinant receptor DDR1:Fc reduces their migration across collagen gel-coated transwells [18]. Moreover, DDR1 overexpression enhances THP-1 monocytic cell line migration in 3D collagen [19]. Despite these findings, the extent to which DDR1 promotes migration of amoeboid cells such as effector T cells in $3 \mathrm{D}$ collagen is still poorly understood.

Th17 are a subpopulation of $\mathrm{T}$ helper cells that are specialized in the production of IL-17. They play important roles in anti-microbial immunity [20], autoimmune diseases [21-23], and have been implicated in tumor growth and anti-cancer immunity [24]. Therefore, it is critical to understand how Th17 cells migrate through the tissue ECM.

In this study, we show that DDR 1 is expressed in human Th17 cells and that it is involved in their migration in $3 \mathrm{D}$ collagen by activating the small GTPase RhoA and its effector Rho-associated kinase (ROCK) and the MAPK/ ERK pathways. Blocking Th17 interactions with collagen using DDR1:Fc reduced the recruitment of Th17 cells into the mouse air pouch containing the chemoattractant CCL20. Together, these results indicate that DDR1 is a critical mediator of Th17 migration through collagen of perivascular tissues.

\section{RESULTS}

\section{Human Th17 cells express DDR1}

We have previously shown that DDR1 expression is induced in human $\mathrm{CD}^{+} \mathrm{T}$ cells upon their activation through the $T$ cell receptor $[18,25]$. Here, we analyzed the expression of DDR1 and DDR2 in human Th17 effector cells. We found that almost all polarized Th17 cells express DDR1 but not DDR2 (Figure 1A). To confirm that IL-17producing cells (Th17 cells) express DDR1, we activated human polarized Th17 cells with PMA+ionomycin to induce IL-17 production, and we determined the expression of DDRs. Flow cytometry analysis showed that the vast majority of Th17 cells express DDR1 but not DDR2 (Figure 1A). Expression analysis on human Th17 cells polarized from five different blood donors showed that between $80-100 \%$ of human Th17 cells express DDR1 (Figure 1B). These results indicate that human Th17 cells preferentially express DDR 1 . In addition, DDR1 is activated by 3D collagen in human polarized Th17 cells. The results showed that collagen gel induced a rapid tyrosine phosphorylation of DDR 1 with a peak at 15 minutes of stimulation, which returns to baseline after $1 \mathrm{~h}$ (Figure 1C). This DDR1 tyrosine phosphorylation kinetic is consistent with that observed with cells growing in suspension such as K562 [26] and B cell lymphoma
[27]. Thus, DDR1 is expressed and is functional in human Th17 cells.

\section{DDR1 is involved in Th17 migration in 3D collagen}

To determine the role of DDR1 in Th17 migration, we first used an RNAi approach and studied Th17 cell motility in $3 \mathrm{D}$ collagen by live cell confocal microscopy. DDR1 specific siRNA (HSS1878780) but not control siRNA reduced total DDR1 protein levels by $80 \%$ (western blot) and DDR1 surface expression by $90 \%$ (FACS) (Figure 2A). DDR1 specific siRNA had no effect on IL-17 production (Figure 2A, lower panel) and on the levels of the CD3 receptor complex (Figure S1), thus supporting the specificity of DDR1 silencing. Polarized Th17 cells that have been transfected with DDR1 siRNA exhibited a dramatic decrease in motility when compared to cells transfected with control siRNA (Figure 2B) and (Video S1). Quantification analysis shows a 75\% reduction in the velocity of DDR1 siRNA-transfected cells (Figure $2 \mathrm{~B}$, right panel). Similar results were obtained with an additional DDR1 siRNA sequence (HSS187879) (Figure $\mathrm{S} 2)$.

As a complementary approach to siRNA, we used the blocking recombinant human receptor DDR1:Fc, which has been shown to block DDR1-mediated cell interactions with collagen $[18,28,29]$. We found that inclusion of recombinant human DDR1:Fc in the collagen gel reduced the motility of polarized human Th17 cells by $80 \%$ when compared to cells migrating in collagen gels containing control recombinant human $\mathrm{IgG}$ (Fc fragment) (Figure 2C). However, DDR1:Fc did not affect neutrophil migration in 3D collagen (Figure S3), which has been shown to be dependent on DDR2 [30], indicating the specificity of DDR1:Fc in inhibiting DDR1. The DDR1:Fc also inhibited the roundish/ellipsoid migratory shape of Th17 cells (Figure 2D), which characterizes the amoeboid movement of activated $\mathrm{T}$ cells in $3 \mathrm{D}$ collagen [31]. The pro-migratory role of DDR1 in Th17 cells is further supported by the fact that Th17 cells released from collagen gels containing DDR1:Fc adhered more to collagen than those released from control collagen gels (Figure S4). This suggests that DDR1 promotes Th17 migration by reducing firm adhesion to collagen, which is consistent with the amoeboid movement of activated $\mathrm{T}$ cells, which occurs independently from strong adhesive forces.

\section{DDR1 promotes Th17 invasion and chemotaxis in 3D collagen}

Then, we examined the role of DDR 1 in invasion and chemotaxis of Th17 cells using collagen gel-coated transwells. Th17 cells express the CCR6 receptor [32] and 


\section{A}
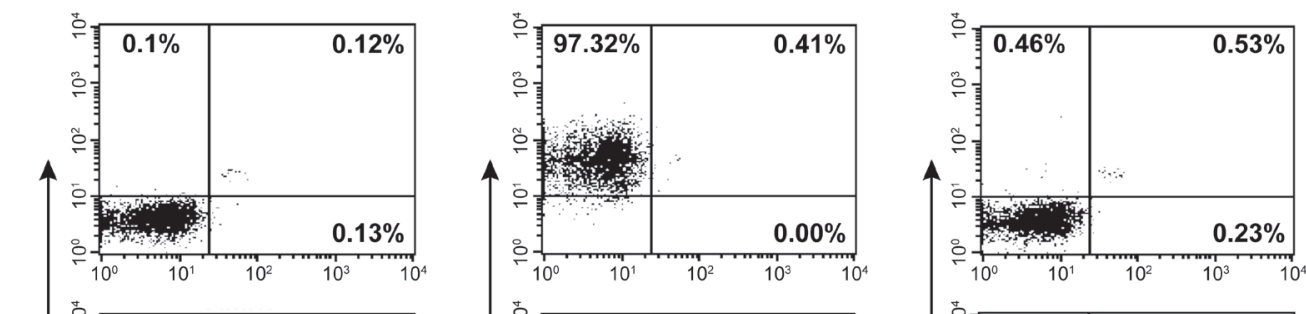

Non-
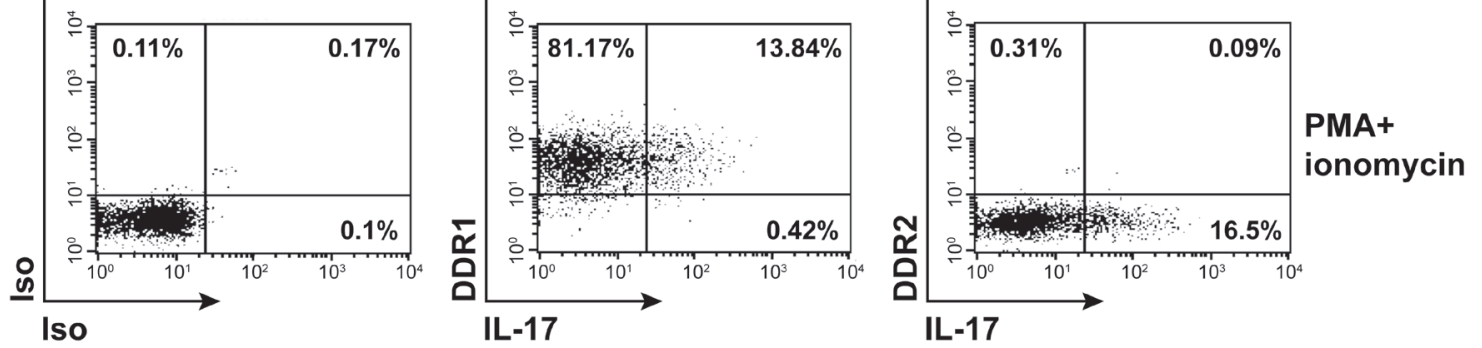

B
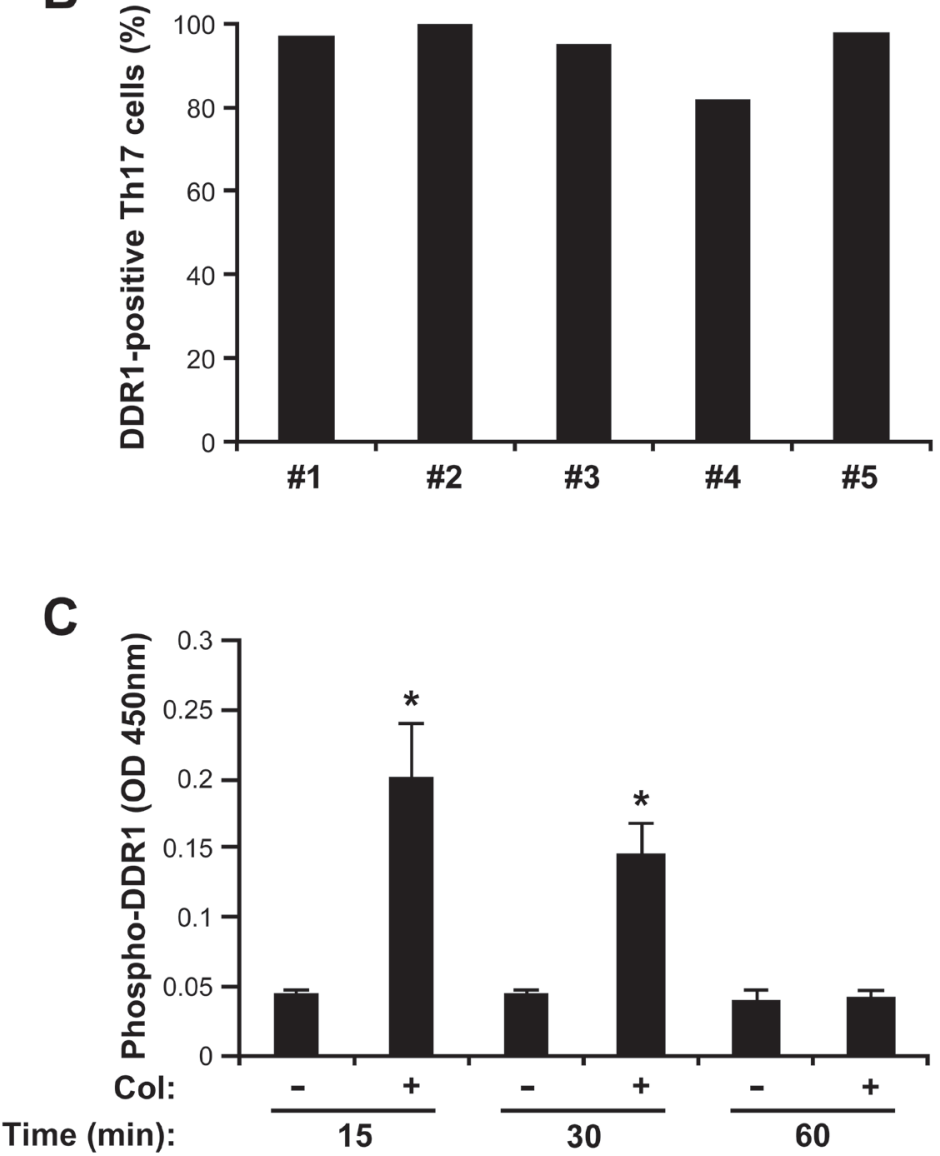

Figure 1: DDR1 is expressed and is functional in human Th17 cells. A. Polarized human Th17 cells were activated or not with PMA+ionomycin for 6 hours in the presence of brefeldin A. The cells were washed and stained with antibodies against DDR1 and DDR2 and with anti-IL-17 mAb to identify IL-17-producing cells as described under the "Materials and Methods" section. Staining with isotypic antibodies (Iso) were used as controls. The cells were then analyzed by flow cytometry. The FACS plots are representative of five different samples. B. The histogram represents percentages of human Th17 cells expressing DDR1 from five different blood donors. C. Collagen induces DDR1 tyrosine phosphorylation. The cells were cultured on plastic (-) or in collagen gels (+) for 15, 30 or 60 min. The cells were lysed and DDR1 tyrosine phosphorylation levels were determined by ELISA assay. The results are mean values \pm SD of five independent experiments performed with polarized Th17 cells derived from five different blood donors. ${ }^{*} p<0.05$. 


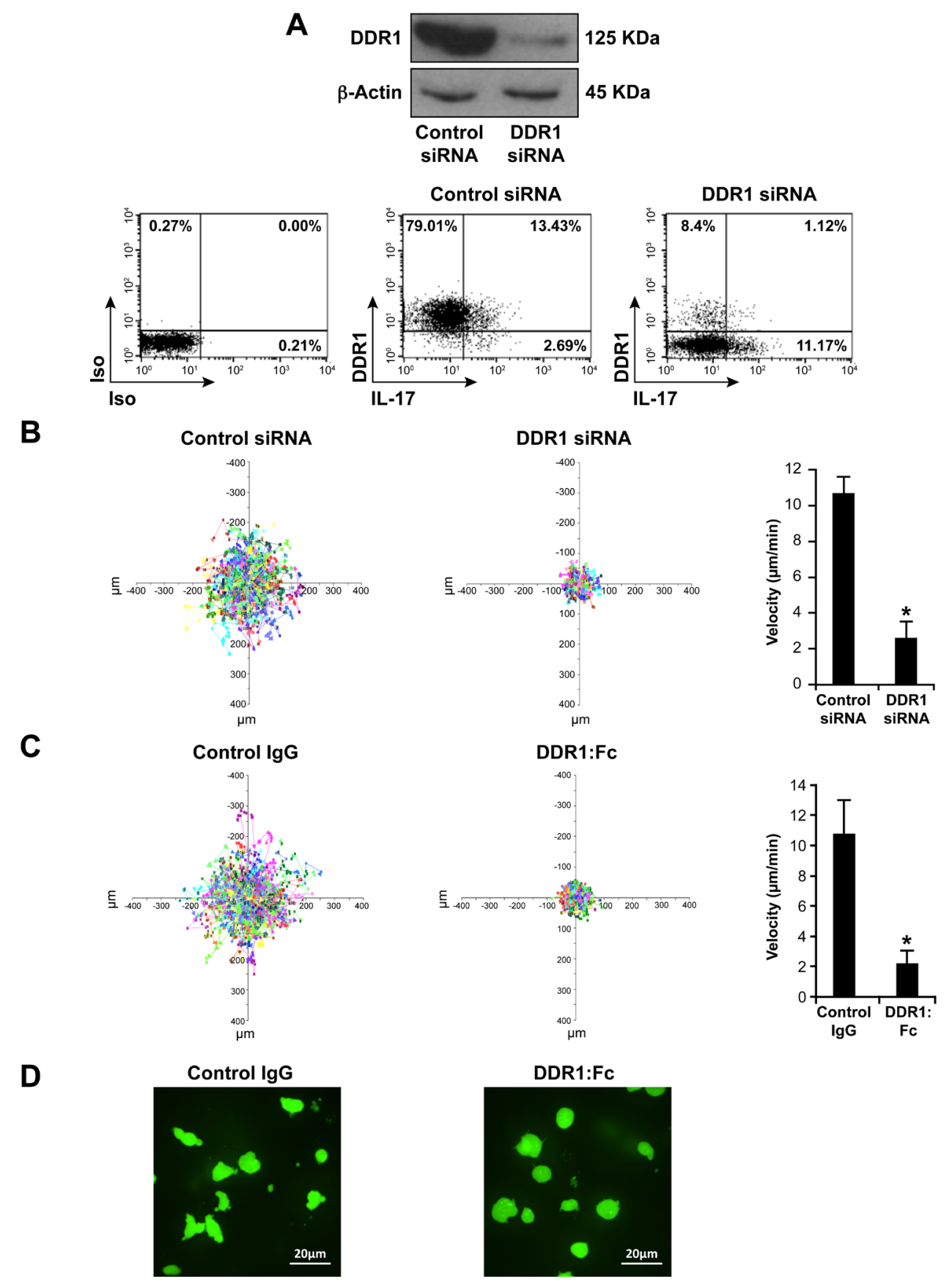

Figure 2: DDR1 promotes human Th17 motility in 3D collagen. A. DDR1 expression is reduced by specific DDR1 siRNA (HSS1878780). Polarized Th17 cells were transfected with control or with DDR1 siRNAs and DDR1 expression was assessed by western blot using the anti-DDR1 antibody (C-20). The blot was stripped and reprobed with anti- $\beta$-actin antibody to ensure equal loading (top panel). After transfection, the cells were activated with PMA+ionomycin in the presence of brefeldin A to identify IL-17-producing cells, stained with anti-DDR 1 and anti-IL-17 antibodies and analyzed by flow cytometry (lower panel). Immunoblot and FACS plots are representative of five independent experiments performed with polarized Th17 cells derived from five different blood donors. B. DDR1 siRNA inhibits Th17 motility in 3D collagen. After transfection, the cells were labelled with calcein AM and embedded in collagen gels. Cell migration was evaluated by live cell confocal microscopy and quantified by computer-assisted cell tracking as described in the "Materials and Methods" section. Representative cell migration tracks over $30 \mathrm{~min}$ are presented as x-y projections (distance, in $\mu \mathrm{m})$ (left panel). The histogram (right panel) represents the mean velocity of 100 cells presented as $\mu \mathrm{m} / \mathrm{min}$. C. DDR1:Fc inhibits Th17 motility in 3D collagen. The cells were embedded in collagen gels containing control human $\operatorname{IgG}$ (Fc fragment) or human DDR1:Fc recombinant proteins and cell motility was determined as above. Results (B and C right panels) are mean values \pm SD of five independent experiments performed with polarized Th17 cells derived from five different blood donors. ${ }^{*} p<0.05$. D. DDR $1: F c$ inhibits the migratory shape of polarized Th17 cells. Representative photography images from five different experiments of polarized Th17 cells migrating in collagen gels containing either control IgG or DDR1:Fc (400X magnification). 
respond to the chemokine CCL20 [32-36]. We found that DDR 1 and CCR6 are co-expressed on $55 \%-65 \%$ of the polarized Th17 cells (Figure 3A). These cells migrated through collagen gel-coated transwells and the presence of CCL2 0 caused a 2.5 fold increase of their migration (Figure 3B and 3C). Transfection of DDR1 siRNA (Figure $3 \mathrm{~B}$ ) or inclusion of DDR1:Fc in the collagen gels (Figure $3 \mathrm{C})$ reduced Th17 invasion by $50-60 \%$ both in the absence and the presence of CCL20. Unlike neutrophil chemotaxis in 3D collagen [30], the pan-MMP inhibitor GM6001 had no effect on Th17 migration and chemotaxis (Figure S5), suggesting that MMPs are not required.

To confirm that migration of IL-17-producing cells in 3D collagen is affected upon DDR1 inhibition, we determined the number of IL-17-producing cells that migrated through collagen gel-coated transwells. To this end, the recovered cells from the outer wells were activated with PMA+ionomycin and analyzed for their production of IL-17 by flow cytometry. The data indicate that the presence of DDR1:Fc reduced the number of Th17 cells migrating randomly and in response to CCL20 (Figure 3D). Although CCR6 is expressed on 55-65\% of the polarized Th17 cells, only $20 \%$ of IL-17-postive cells migrated towards CCL20 (maximum observed). This is in line with the fact that not all CCR6-positive cells produce IL-17 [37]. Taken together, these results demonstrate an important role for DDR1 in human Th17 cell migration in $3 \mathrm{D}$ collagen.

\section{DDR1-induced Th17 migration involves the RhoA/ROCK pathway}

We then investigated the mechanisms by which DDR1 promotes Th17 migration in 3D collagen. The Rho family of small GTPases are important signaling molecules in cell migration but their role in $\mathrm{T}$ cell movement in $3 \mathrm{D}$ collagen has not been previously addressed. Thus, we examined the implication of RhoA and of its effector, the kinase ROCK. We found that only collagen gel (3D) but not coated monomeric collagen (2D) activated RhoA and ROCK (Figure 4A). The use of collagenase to release the cells from collagen had no effect on RhoA or ROCK activity (data not shown). To determine the implication of RhoA and ROCK in Th17 migration, we used specific inhibitors, namely the $\mathrm{C} 3$ toxin (RhoA inhibitor) and Y27632 (ROCK inhibitor). Both inhibitors strongly decreased Th17 motility (Figure 4B) as well as Th17 invasion and chemotaxis in collagen gel-coated transwells (Figure 4C). Although CCL20 caused a two-fold increase of RhoA activation, it had no additional or inhibitory effect in cells stimulated with collagen gel (data not shown). We then asked whether DDR1 inhibition would impact RhoA/ROCK activation. We found that DDR1 siRNA and DDR1:Fc decreased RhoA activation by $50 \%$ and that of ROCK by $65-75 \%$ in Th17 cells cultured in collagen gels (Figure 5A and 5B).
Since the small GTPase Rac1 can inhibit the amoeboid movement [38, 39], we verified its implication in Th17 migration. We found that collagen gel reduces Rac1 activity and blocking DDR1 restored its activity (Figure S6). In addition, the Rac1 inhibitor enhanced Th17 migration. Taken together, these data indicate that increased activation of RhoA/ROCK and decreased Rac1 activity, through DDR1, are important for Th17 migration in $3 \mathrm{D}$ collagen.

\section{DDR1-induced Th17 migration involves the MAPK/ERK pathway}

3D collagen has been associated with the activation of MAPK/ERK, which is an important pathway in cell migration. We therefore examined its implication in human Th17 migration.

After $1 \mathrm{~h}$ of stimulation, collagen gel increased ERK phosphorylation and this effect was mediated via DDR1 since it was abolished in DDR1 siRNA-transfected cells (Figure 6A). Similar results were obtained when the cells were cultured in collagen gels for 2 or $3 \mathrm{~h}$ (Data not shown). In addition, the MAPK/ERK inhibitor PD98059 strongly reduced Th17 cell motility (Figure 6B) and invasion (Figure 6C) in collagen gels, and expression of a dominant-negative form of MEK-1 (DN-MEK-1) also reduced Th17 migration (Figure 6D). Together, these data support the implication of the MAPK/ERK pathway in Th17 migration in 3D collagen.

We also found that ERK activation was dependent on the RhoA/ROCK pathway since the C3 and Y27632 inhibitors abolished the ability of collagen gel to phosphorylate ERK in Th17 cells (Figure 7A). However, the PD98059 inhibitor had no effect on RhoA/ROCK activation (Figure 7B) indicating that ERK is downstream of RhoA/ROCK. Therefore, DDR1 promotes human Th17 migration in $3 \mathrm{D}$ collagen by activating the RhoA/ROCK/ MAPK/ERK signaling axis.

\section{DDR1 promotes Th17 cell migration in vivo}

To determine the role of DDR1 in vivo, we used the mouse dorsal s.c air pouch model of leukocyte migration. In this model, Th17 cells can be recruited into the air pouch in response to the chemokine CCL20 [36]. We found that $\mathrm{IL}-17^{+}$cells represents $9 \%$ of the total $\mathrm{CD}^{+}$ $\mathrm{T}$ cell population recruited into the air pouch and that DDR 1 is expressed in $80 \%$ of the recruited Th17 cells (Figure 8A). We then tested whether inhibiting DDR1 activity might influence Th17 recruitment. To this end, we injected the air pouches with blocking recombinant mouse DDR1:Fc receptor or with control recombinant mouse IgG (Fc fragment only), and the cells that had migrated in response to CCL20 after $24 \mathrm{~h}$ were analyzed by flow cytometry. We found that DDR1:Fc inhibited the 

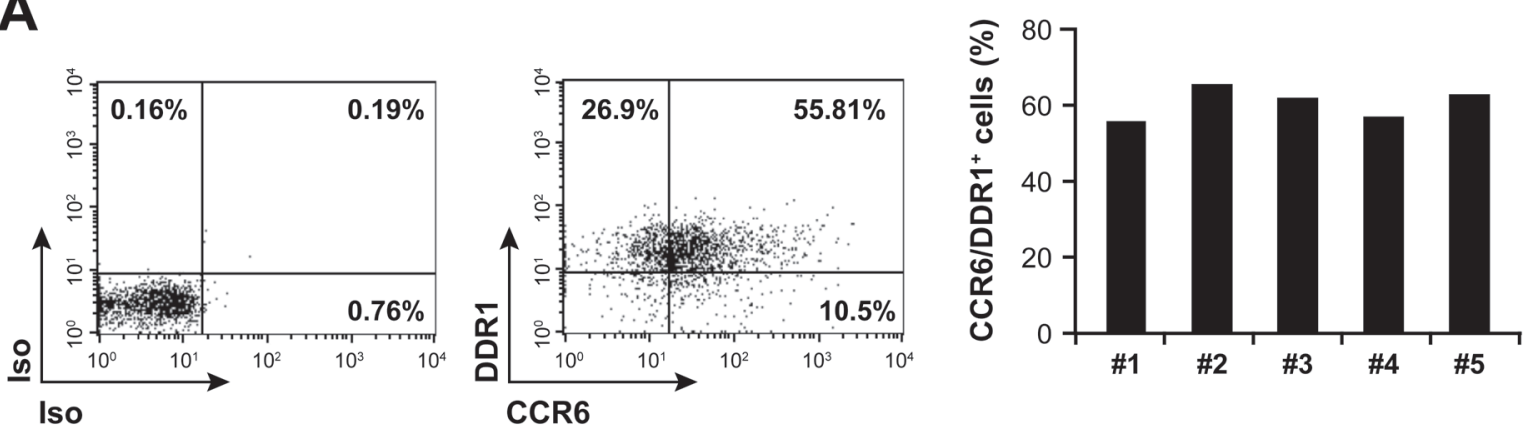

B

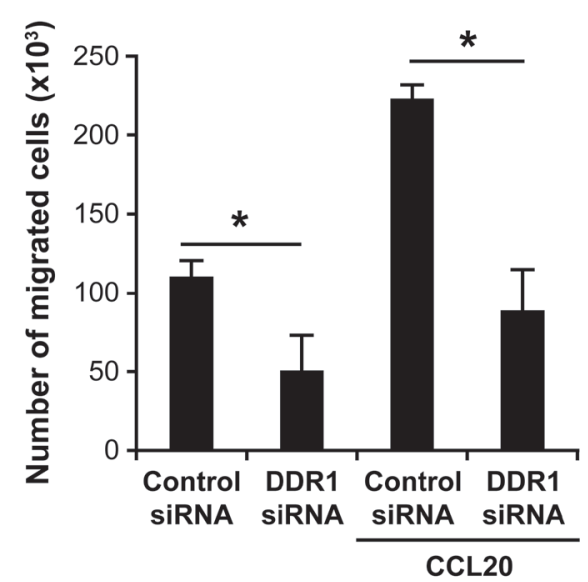

C

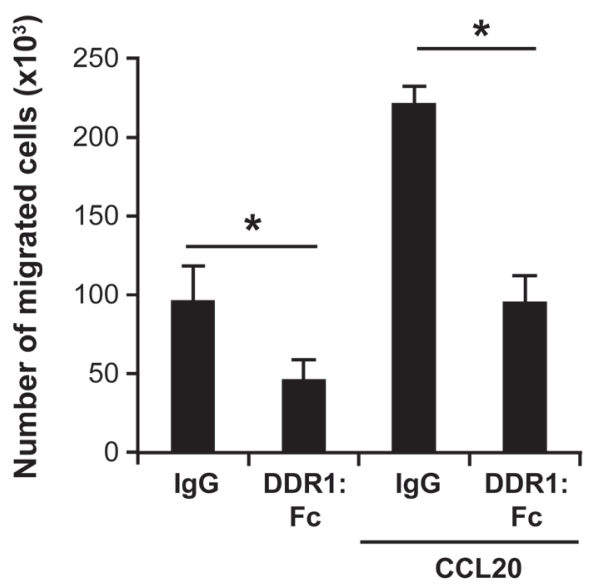

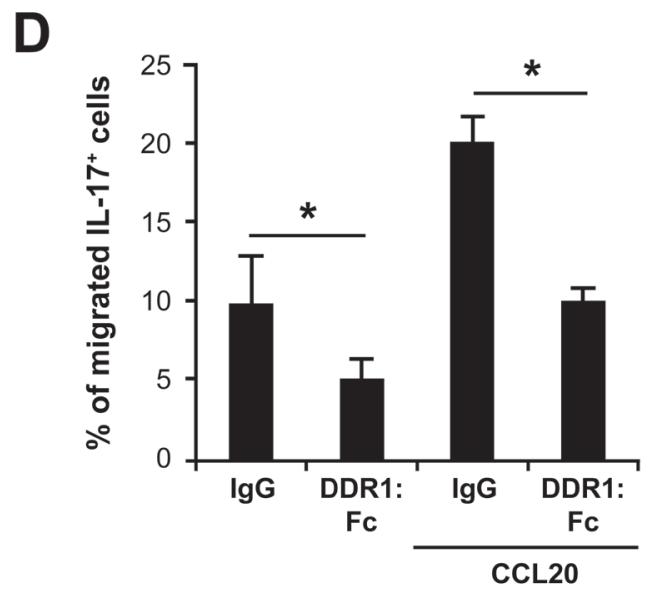

Figure 3: DDR1 promotes invasion and chemotaxis of human Th17 cells in 3D collagen. A. Polarized human Th17 cells co-express CCR6 and DDR1. The cells were stained with anti CCR6 and anti-DDR1 or with control isotypic (Iso) antibodies and analyzed by flow cytometry. The FACS plots are representative of five different samples (left panel). The histogram represents percentages of polarized Th17 cells co-expressing CCR6 and DDR1 derived from five different blood donors. B. DDR1 silencing reduces invasion and CCL20-directed migration of polarized Th17 cells in 3D collagen. The cells transfected with DDR1 or control siRNAs were added on top of collagen gel-coated transwells. After $24 \mathrm{~h}$, cells that had passed to the other side of the transwells and in the outer wells, which contained $\mathrm{X}$-vivo medium with or without $1 \mu \mathrm{g} / \mathrm{ml}$ of CCL2 20 were recovered and counted microscopically. C. Effect of DDR1:Fc on invasion and on CCL20-directed migration of Th17 cells through 3D collagen. Cells were added on the top of collagen gels containing recombinant human DDR1:Fc or control IgG (Fc fragment) proteins. After $24 \mathrm{~h}$, cells that had passed to the outer wells were counted. D. Effect of DDR1:Fc on invasion and CCL20-directed migration of IL-17-producing cells. Cells that have migrated through collagen gel-coated transwells were recovered from the lower chambers and activated with PMA+ionomycin in the presence of brefeldin A to identify IL-17-producing cells. The cells were fixed/permeabilized, stained with anti-IL-17-Alexa-647 mAb and analyzed by flow cytometry. Results (panels B, C and D) are mean values $\pm \mathrm{SD}$ of five independent experiments performed with Th17 cells derived from five different blood donors. ${ }^{*} p<0.05$. 
A
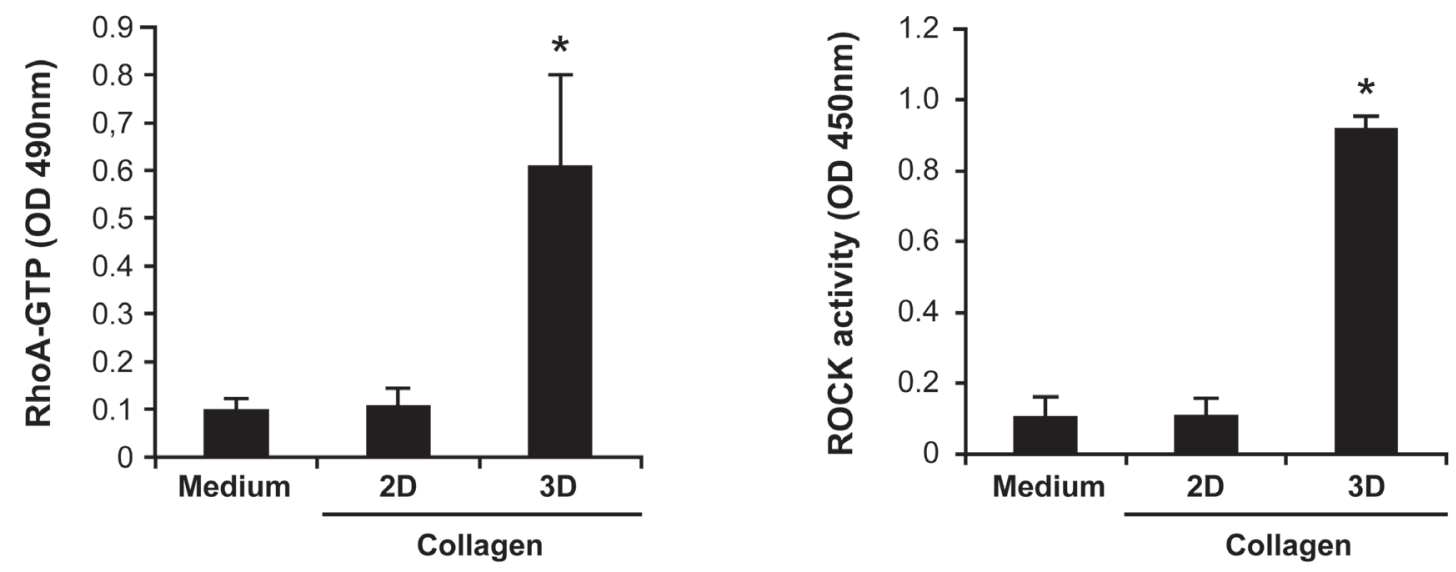

B
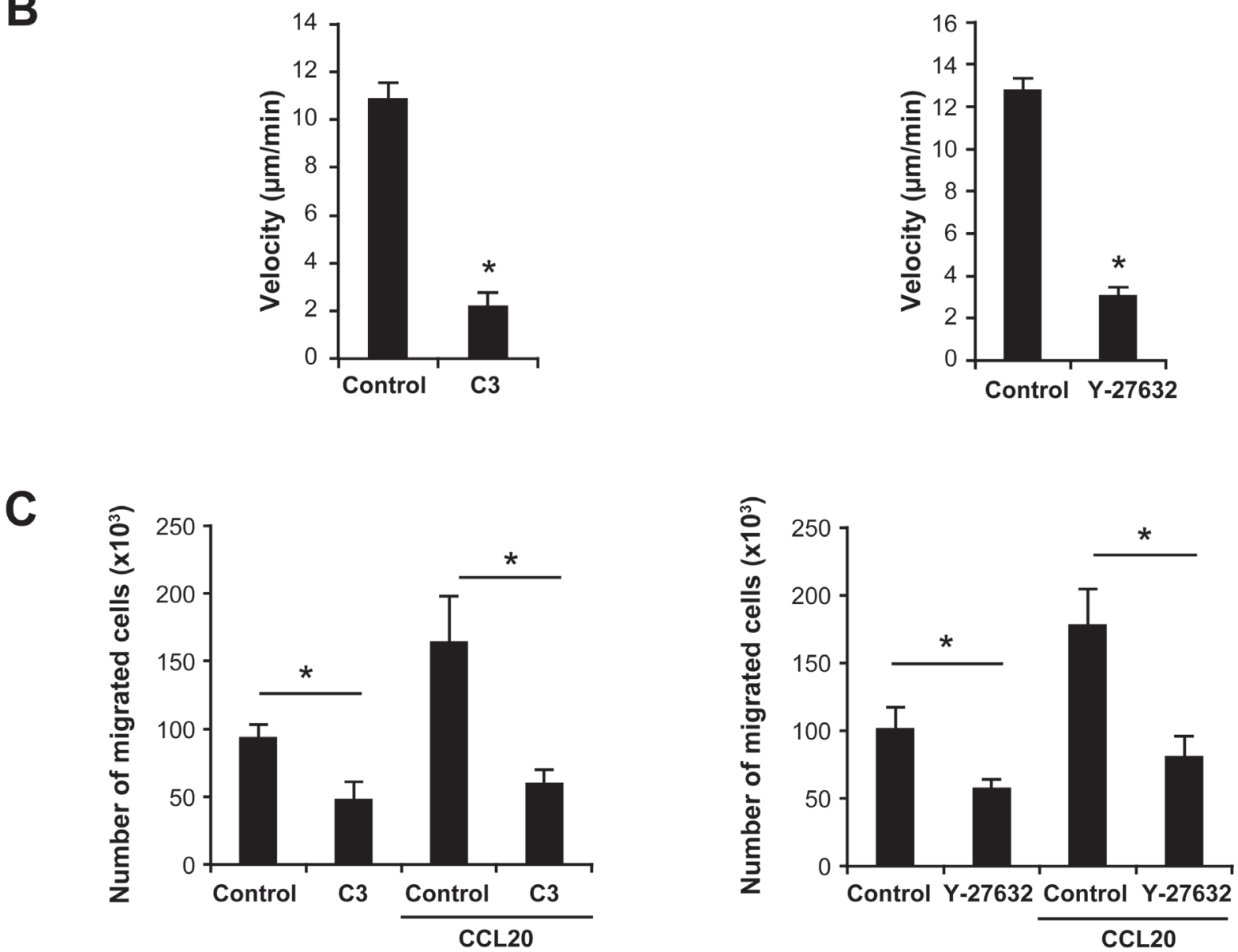

Figure 4: Th17 migration in 3D collagen involves the RhoA/ROCK signaling pathway. A. 3D collagen increases RhoA and ROCK activation. Th17 cells were cultured on plastic (medium), on monomeric immobilized collagen (2D) or in collagen gels (3D) for $1 \mathrm{~h}$. The cells were released from collagen gels after a collagenase treatment and equal cell numbers were lysed in RIPA buffer. GTPbound RhoA levels and ROCK activity were measured using specific RhoA G-LISA and ROCK ELISA, respectively. B. RhoA/ROCK inhibitors reduce Th17 cell migration. Th17 cells were incubated or not for $1 \mathrm{~h}$ with diluent (control) or with $1 \mu \mathrm{g} / \mathrm{ml}$ of the RhoA inhibitor (C3 toxin) or with $30 \mu \mathrm{M}$ of the ROCK inhibitor (Y-27632) and embedded in collagen gels. Cell migration was evaluated by live cell confocal microscopy and quantified by computer-assisted cell tracking as described in the "Materials and Methods" section. C. RhoA/ ROCK inhibitors inhibit CCL20-directed migration of Th17 cells in 3D collagen. The cells were incubated as above with the RhoA/ ROCK inhibitors and tested for their invasion capacity of collagen gel-coated transwells. Cells that had passed to the outer wells containing medium alone or with CCL20 were then counted microscopically. Results (panels A, B and C) are mean values \pm SD of three independent experiments performed with Th17 cells derived from three different blood donors. ${ }^{*} p<0.05$. 
migration of $\mathrm{CD}^{+} \mathrm{T}$ cells by almost $60 \%$ and that of Th17 cells (IL-17-producing CD $4^{+}$cells) by almost $85 \%$ (Figure $8 \mathrm{~B})$. These results demonstrate that DDR1 is involved in Th17 migration in perivascular tissue.

\section{DISCUSSION}

In this study, we report that the collagen receptor DDR1 plays a key role in Th17 cell migration. We showed that DDR1 promotes the motility and invasion of Th17 cells in 3D collagen and in perivascular tissues in vivo. In addition, DDR1 enhances Th17 migration by activating the RhoA/ROCK/MAPK/ERK signaling pathway.

DDR1 and DDR2 are widely expressed receptors and are considered to be collagen sensors. They play important roles in cell proliferation, adhesion and migration [11, 12]. Our results showed that human Th17 cells preferentially express DDR1 and inhibition of its activity (siRNA and DDR1:Fc) strongly reduced human Th17 motility, invasion and chemotaxis in 3D
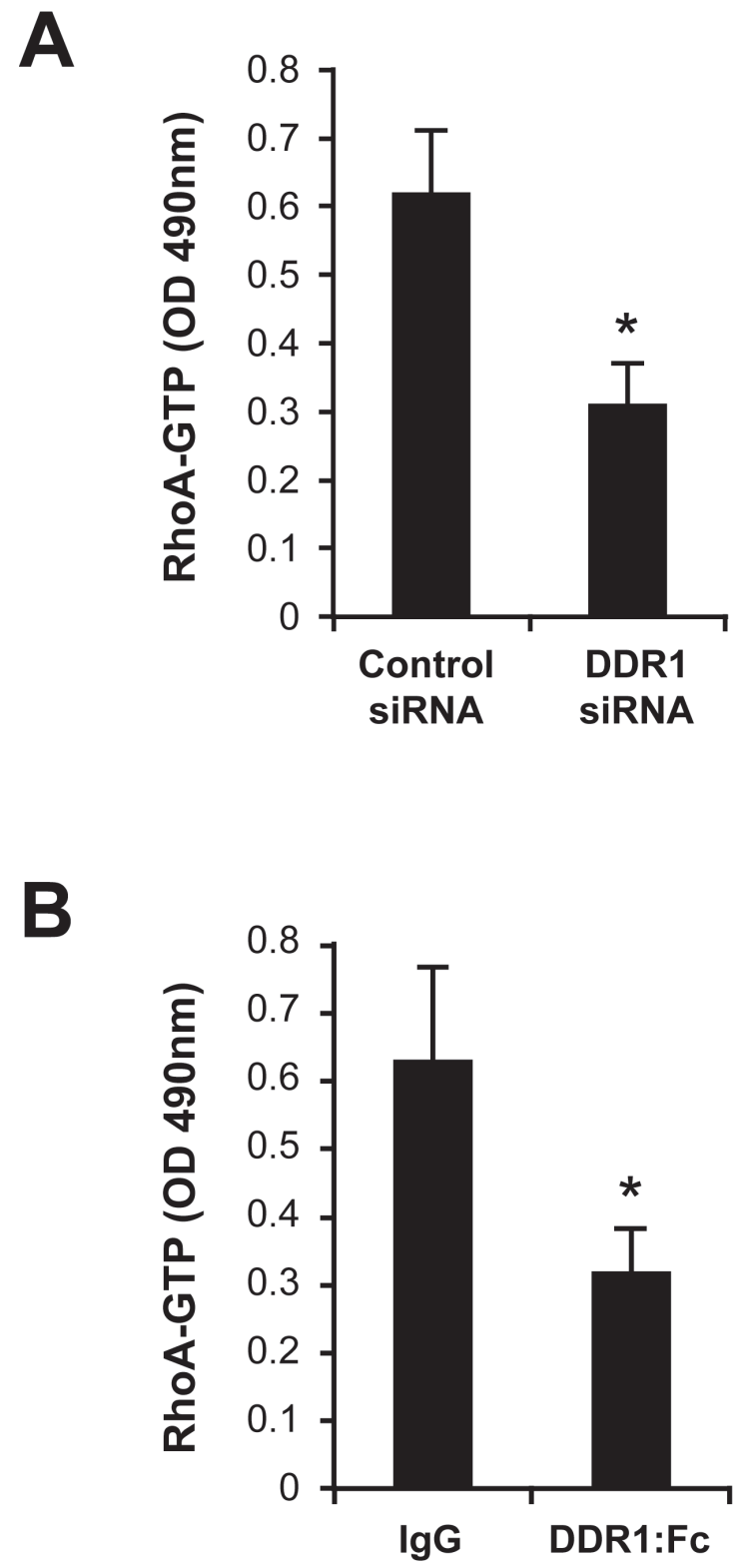
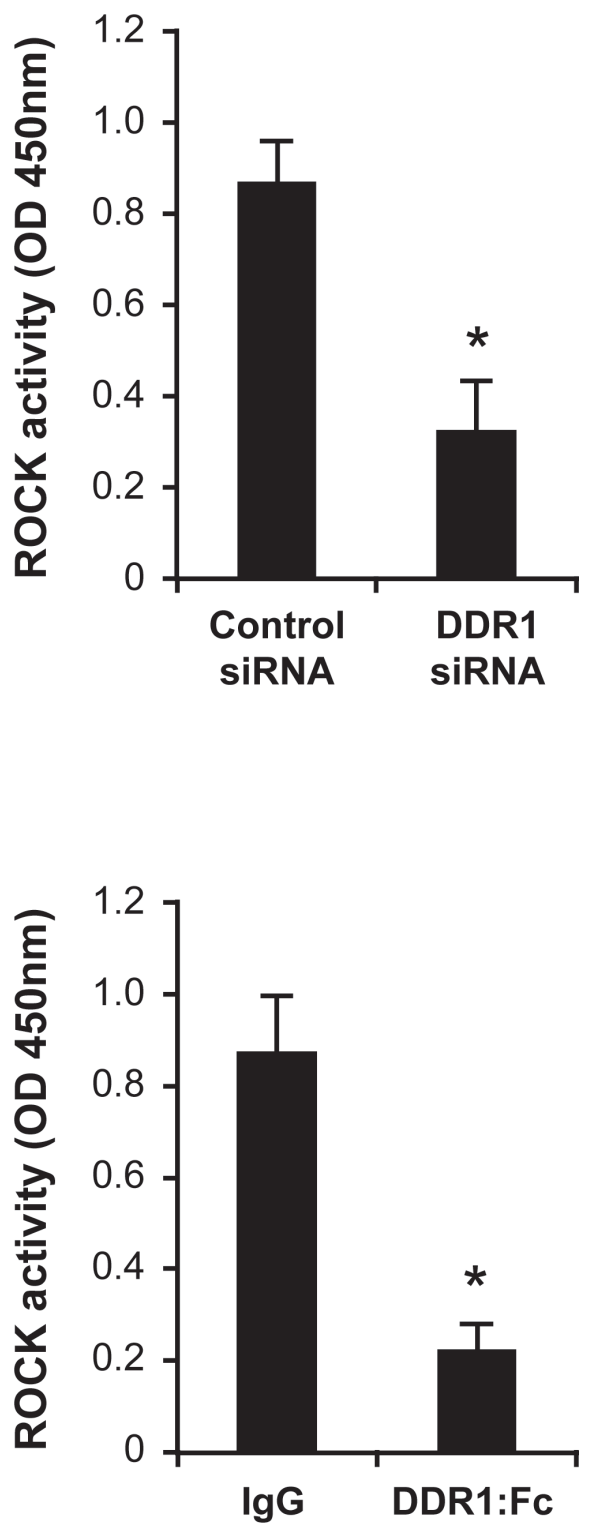

Figure 5: Inhibition of DDR1 decreases RhoA/ROCK activity in Th17 cells cultured in 3D collagen. A. Effect of DDR1 siRNA on collagen gel-induced RhoA/ROCK activation. Cells were transfected with control or DDR1 siRNAs and embedded in collagen gels for $1 \mathrm{~h}$. The cells were released from collagen, lysed and GTP-bound RhoA and ROCK activity were determined. B. Effect of DDR1:Fc on RhoA/ROCK activity. The cells were embedded in collagen gels containing control recombinant human IgG (Fc fragment) or DDR1:Fc proteins and after $1 \mathrm{~h}$, RhoA and ROCK activities were determined. Results are mean values $\pm \mathrm{SD}$ of three independent experiments performed with Th17 cells derived from three different blood donors. ${ }^{*} p<0.05$. 
collagen. This is associated with the loss of the amoeboid morphology of the migrating cells and with their increased adhesion to collagen suggesting that DDR1 promotes Th17 migration by reducing firm adhesion to collagen. Along these lines, although DDR1 enhances migration of various cancer cells by increasing adhesion to collagen [40-42], it does not always promote cell adhesion. DDR1 binding to collagen inhibits MDCK epithelial cell adhesion to collagen [43] and spreading of NIH-3T3 and MDAMB-231 cells [44], while promoting their migration. Moreover, and in contrast to DDR2, DDR1 is unable to consistently mediate firm adhesion to collagen [45]. Thus,

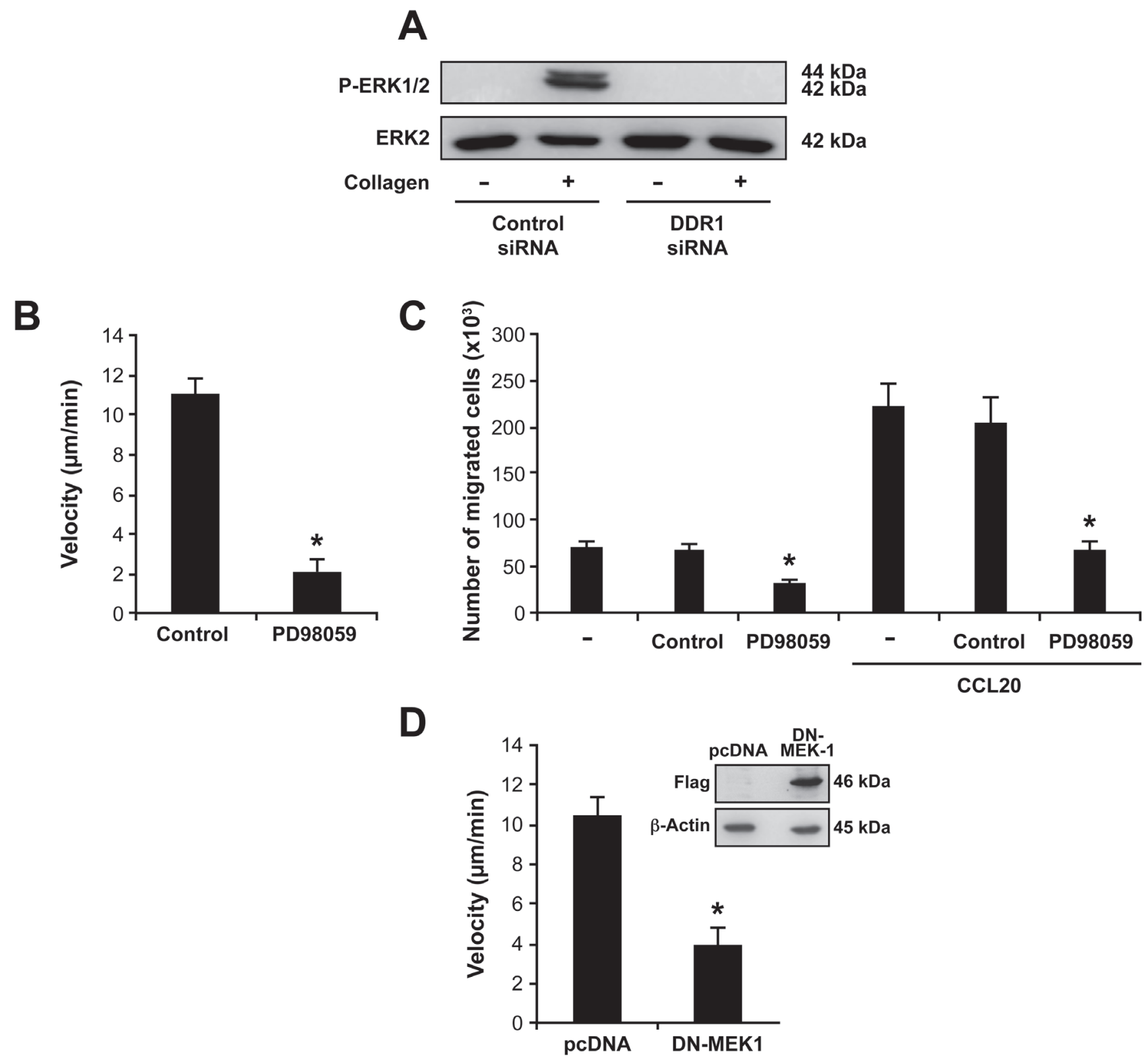

Figure 6: DDR1 promotes Th17 migration by activating the MAPK/ERK pathway. A. DDR1 silencing inhibits collagen gel-induced ERK1/2 phosphorylation. The cells were transfected with DDR1 or control siRNAs, embedded in collagen gels for $1 \mathrm{~h}$ and then ERK1/2 phosphorylation was determined by western blot. The blot was stripped and reprobed with anti-ERK2 to ensure equal loading. B.-C. The MAPK/ERK inhibitor reduced Th17 cell migration in 3D collagen. The cells were cultured alone (-) or with the MAPK/ERK inhibitor PD98059 $(20 \mu \mathrm{M})$ or diluent (control) for $1 \mathrm{~h}$ and then tested for their capacity to migrate. Cell migration in 3D collagen was evaluated by live cell confocal microscopy B. and by invasion of collagen gel-coated transwells C.. D. Dominant-negative form of MEK-1 (DN-MEK-1) reduces Th17 cell migration in collagen. The cells were transfected with control pcDNA and DN-MEK-1 plasmids and their migration was determined by confocal microscopy. The western blot shows the expression of DN-MEK-1 (flag-tagged) in control and in DN-MEK-1-transfected cells. Results (panels B, C and D) are mean values \pm SD of three independent experiments performed with Th17 cells derived from three different blood donors. ${ }^{*} p<0.05$. 
in cells that migrate using the amoeboid movement such as effector T cells, which rely on low adhesive forces, DDR1 binding to collagen might lessen strong attachment; thereby allowing cell movement. The mechanisms by which DDR1 could reduce firm adhesion are unclear but, as seen in MDCK cells [43], it can inhibit integrin pathways, which mediate strong adhesion to collagen.

Activation of the small GTPase RhoA and its effector ROCK have been involved with the amoeboid movement [46-48]. Herein, we found that 3D collagen increases RhoA and ROCK activation in a DDR1dependent manner, and inhibition studies indicated that the RhoA/ROCK pathway is critical for Th17 migration in 3D collagen. Concomitantly, 3D collagen reduced Rac1 activity, also in a DDR1-dependent manner, and inhibiting Rac1 activity enhanced Th17 migration in 3D collagen. This is consistent with previous findings indicating that Rac1 promotes cell elongation and mesenchymal-type of migration, and inhibits the amoeboid movement [38, 39]. Thus, Th17 migration in $3 \mathrm{D}$ collagen is associated, through DDR1, with increased RhoA/ROCK and decreased Rac1 activity.

In addition to Rho GTPases, we showed that DDR1- induced Th17 migration is dependent on MAPK/ERK activity, which is an important pathway in cell migration. We found that 3D collagen increases ERK phosphorylation in Th17 cells via DDR1 and that RhoA and ROCK lie upstream of MAPK/ERK activation. In contrast to our findings, ERK has recently been shown to phosphorylate and activate RhoA [49]. In addition, Annexin-A1 increases breast cancer invasion by activating RhoA in an ERK-dependent fashion. However, in this model, RhoA inhibition also reduced ERK phosphorylation [50] suggesting that the two pathways can influence each other. Based on our data, we propose that DDR1 promotes the amoeboid movement of human Th17 cells in 3D collagen by activating the RhoA/ROCK/MAPK/ERK signaling axis. It is not clear whether RhoA/ROCK stimulates Th17 migration independently from ERK. However, this is plausible since both ERK and RhoA/ROCK work in a complementary manner to support urokinasetype plasminogen activator-stimulated cell migration [51]. Thus, our results identified an additional pathway activated by DDR1, which is of critical importance for effector $\mathrm{T}$ cell migration in $3 \mathrm{D}$ collagen.

Our findings also support a role for DDR1 in Th17
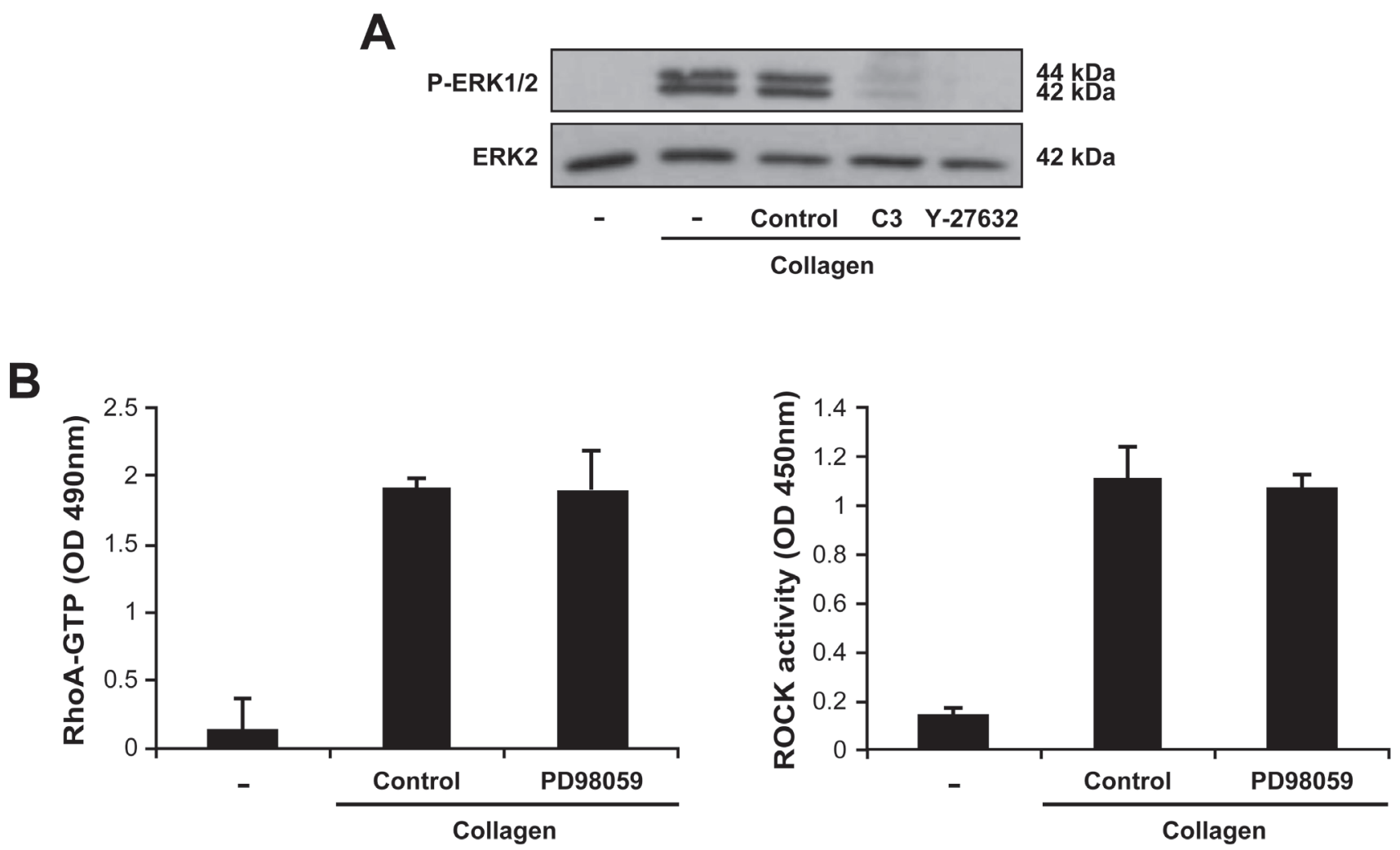

Figure 7: The MAPK/ERK is downstream of RhoA/ROCK in Th17 cells. A. RhoA and ROCK are necessary for 3D collageninduced ERK activation. The cells were incubated for $1 \mathrm{~h}$ in medium alone (-) or in medium containing C3 toxin or Y-27632 inhibitors. The cells were then embedded in collagen gels for $1 \mathrm{~h}$, after which, ERK1/2 phosphorylation was determined by western blot. The results are representative of three independent experiments. B. The MAPK/ERK inhibitor had no effect on 3D collagen-induced RhoA and ROCK activation. The cells were cultured for $1 \mathrm{~h}$ in medium alone (-) or in medium containing the MAPK/ERK inhibitor PD98059 (20 $\mu$ M) or diluent (control) and then embedded in collagen gels. After $1 \mathrm{~h}$, RhoA and ROCK activities were measured by ELISA assays. Results are mean values \pm SD of three independent experiments performed with Th17 cells derived from three different blood donors. 
chemotaxis in 3D collagen. Recently, it has been reported that IL-8- and LTB-4-induced chemotaxis of neutrophils in $3 \mathrm{D}$ collagen involves DDR2-mediated proteolysis via the secretion of MMP-8 [30]. However, DDR1-mediated Th17 chemotaxis in 3D collagen occurred independently from MMP activity. Therefore, the implication of MMPs in chemotaxis could be leukocyte type-dependent.

Using the mouse dorsal air pouch model of leukocyte migration, we provided, to our knowledge, the first evidence that DDR1 is implicated in T cell migration in vivo. Collagen is abundant in the skin, and to reach the air pouch, $\mathrm{T}$ cells must migrate through the endothelial

A
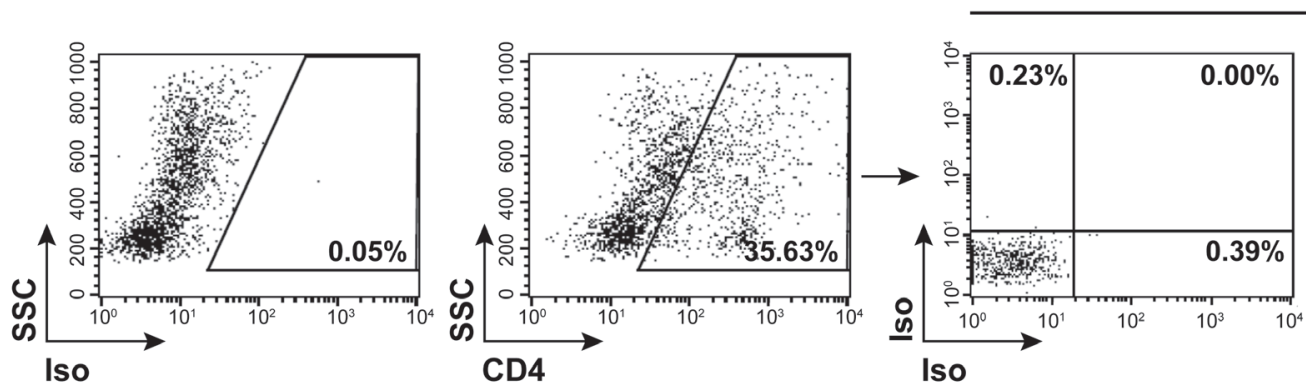

CD4+ cells

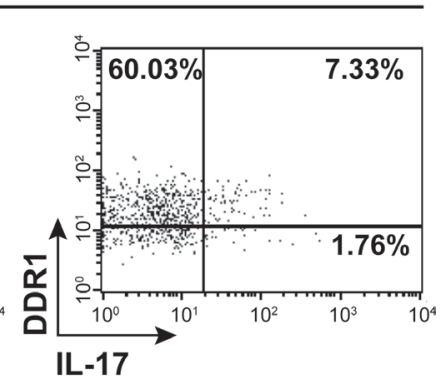

B
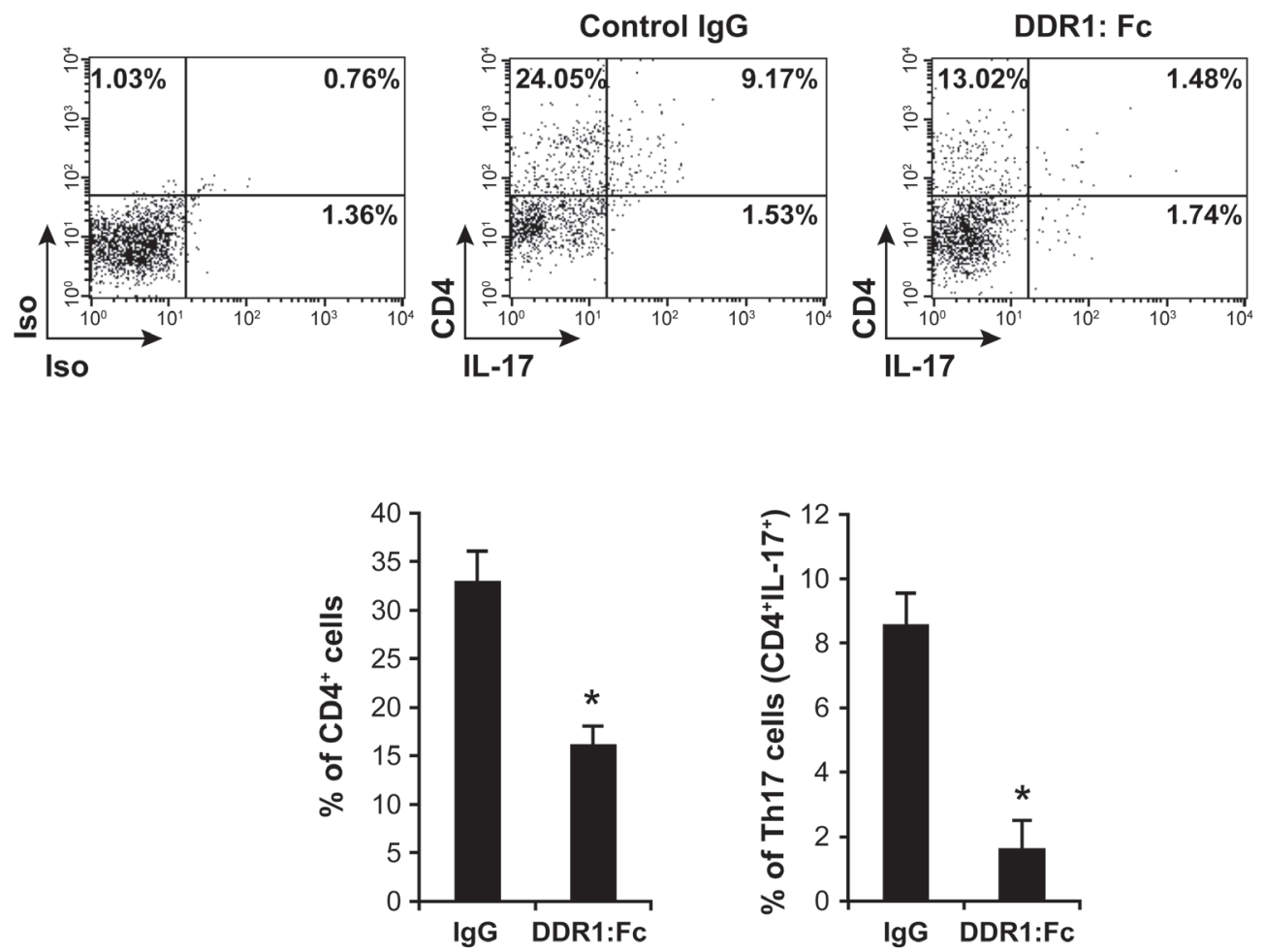

Figure 8: DDR1 promotes Th17 migration in vivo. A. Th17 cells recruited into mouse dorsal air pouch express DDR1. Air pouches were raised as described in the "Materials and Methods" section. The cells were recovered from air pouches $24 \mathrm{~h}$ after the injection of CCL20 and were activated with PMA+ionomycin in the presence of brefeldin A to identify IL-17-positive cells. The cells were stained with anti-CD4, then with intracellular anti-DDR1 and anti-IL-17 antibodies and analyzed by flow cytometry. Staining with isotypic antibodies (Iso) were used as controls. DDR1/IL-17-positive cells in the right panel are gated on the CD4 positive population. The FACS plots are representative of ten mice $(n=10)$. B. DDR1:Fc inhibits Th17 recruitment into the air pouch. Mouse recombinant DDR1:Fc or control IgG (Fc fragment) proteins were injected into the air pouches at the same time as CCL20. After $24 \mathrm{~h}$, the cells were recovered, activated with PMA+ionomycin in the presence of brefeldin A, stained with anti-CD4 and anti-IL-17 antibodies and analyzed by flow cytometry. The FACS plots are representative of ten mice. The histogram represents mean values $\pm \mathrm{SD}(n=10)$ of $\mathrm{CD} 4^{+}$and $\mathrm{CD} 4^{+} / \mathrm{IL}_{-1} 7^{+}(\mathrm{Th} 17)$ cells recovered from control IgG- or DDR1:Fc-treated air pouches. ${ }^{*} p<0.05$. 
cell layer and overcome the collagen barrier of the extravascular tissue. Thus, the DDR1:Fc blocking receptor reduced the number of Th17 cells in the air pouches likely by preventing them from migrating across collagen. These results support the findings with human polarized Th17 cells suggesting that the function of DDR1 in these cells is not simply due to the in vitro differentiation and activation. Accordingly, DDR1 may play an important biological role by facilitating the migration and the positioning of effector $\mathrm{T}$ cells in collagen-rich tissues during adaptive immune response and autoimmune diseases. This could be the case during chronic arthritis or psoriasis, which are associated with the recruitment of Th17 cells into the joints and skin and where collagen is a predominant matrix protein. Therefore, blocking DDR1 could represent a novel therapeutic strategy in these diseases and other connective tissue diseases driven by Th17 cells. However, additional work is required to investigate the importance of DDR1 in different biological systems.

DDR1 inhibition decreased the recruitment into the air pouch of not only Th17 cells but also of non-Th17/ $\mathrm{CD}^{+} \mathrm{T}$ cells. The human polarized Th17 cells used in this study contain Th1 cells [52] and our results suggest that these cells also depend on DDR1. These data indicate that DDR1 could also be important for the migration of other T helper subsets.

In summary, we have shown that DDR1 is a key pathway in the migratory function of Th17 cells. The calreticulin-thrombospondin-1 interaction has been described as an autocrine pathway regulating $\mathrm{T}$ cell migration in 3D collagen [53]. Whether there is a crosstalk between these two pathways is unclear. Further understanding of how DDR1 stimulates T cell migration in collagen and in extravascular tissues will likely lead to novel insights into the development of the adaptive immune response, inflammatory diseases and metastasis.

\section{MATERIALS AND METHODS}

\section{Reagents and antibodies}

$\mathrm{X}$-vivo 15 medium and the human $\mathrm{T}$ cell nucleofector kit were from Lonza technologies (Basel, Switzerland). PMA, ionomycin, collagenase IV, ROCK inhibitor (Y27632) and the general MMP inhibitor (GM6001) were from Sigma-Aldrich (St. Louis, MO). Human cytokines (TGF- $\beta$, IL-1 $\beta$, IL-6, IL-23), the chemokine CCL20, the recombinant human and mouse blocking receptors DDR1:Fc and their respective isotypic controls, the recombinant human and mouse IgG-Fc fragments (control IgGs) were from R\&D Systems (Minneapolis, MN). The human naïve $\mathrm{CD}^{+} \mathrm{T}$ cell isolation kit was from STEMCELL Technologies (Vancouver, BC). Rat-tail type I collagen was from
Corning (Bedford, MA). Anti-mouse CD4-FITC (clone RM4-5), anti-human CCR6-Alexa 647 (clone 11A9), antimouse IL-17-Alexa 647 (clone TC11-18H10), anti-human IL-17-Alexa 647 (clone N49-653), and control antibodies were from BD Biosciences (San Diego, CA). Human antiDDR1-PE (clone 51D6) was from Biolegend (San Diego, CA). Non-conjugated rabbit anti-mouse and human DDR1 (clone C-20), non-conjugated rabbit anti-human DDR2 (clone H108) antibodies and the anti-phospho-ERK1/2 (clone E-4), anti-ERK2 (clone C-14), and anti- $\beta$-actin (clone C-2) Abs were from Santa Cruz Biotechnology (Santa Cruz, CA). CD3/CD28 Dynabeads were from Invitrogen Dynal AS (Oslo, Norway). C3 toxin (RhoA inhibitor) and G-LISA kits for RhoA and Rac1 activities were from Cytoskeleton Inc (Denver, CO). ROCK Activity Assay was from Cell Biolabs (San Diego, CA). The Rac1 inhibitor NSC 23766 was from Tocris Bioscience (Bristol, UK). Calcein-AM and the MAPK/ERK inhibitor PD98059 were from Calbiochem (San Diego, CA).

\section{Human Th17 cells}

Human naïve $\mathrm{CD}^{+} \mathrm{T}$ cells were isolated from peripheral blood of healthy adult volunteers according to the requirements of and with the approval of the Laval University ethical committee. The cells were then polarized towards Th17 cells as we previously described [54].

\section{DDRs expression, IL-17 intracellular staining and flow cytometry}

To identify IL-17 producing cells, human polarized Th17 cells were activated or not with PMA $(50 \mathrm{ng} / \mathrm{ml})$ and ionomycin $(1 \mu \mathrm{M})\left(6 \mathrm{~h}\right.$ at $\left.37^{\circ} \mathrm{C}\right)$ in the presence of 5 $\mu \mathrm{g} / \mathrm{ml}$ GolgiPlug (BD Biosciences) containing brefeldin A to interfere with cytokine secretion. The cells were first stained with PE-conjugated extracellular anti-DDR1 antibody, washed, fixed and permeabilized with a CytoFix/ CytoPerm kit and stained with intracellular Alexa-647conjugated anti-human IL-17 antibody. To detect DDR2 expression, permeabilized cells were stained with rabbit intracellular anti-human DDR2 antibody followed with PE-conjugated anti-rabbit IgG secondary antibody. The cells were washed and stained with intracellular antiIL-17-Alexa-647 antibody. After staining, the cells were washed and analyzed by flow cytometry (BD FACSCalibur II). Cells stained with isotypic antibodies were used as controls.

\section{Collagen gel and coating}

Collagen gels were prepared by diluting rat-tail type I collagen to a final concentration of $1.65 \mathrm{mg} / \mathrm{ml}$ in 
$\mathrm{X}$-vivo medium and adjusted to $\mathrm{pH} 7.4$ with $\mathrm{NaOH}$. The cells were mixed with this solution and the suspension was allowed to polymerize $\left(1 \mathrm{~h}\right.$ at $\left.37^{\circ} \mathrm{C}\right)$ in 8 well-Lab-Tek plates or in 24 well-plates, respectively for cell migration and signaling experiments.

For collagen coating (2D), rat-tail type I collagen was diluted in PBS to $100 \mu \mathrm{g} / \mathrm{ml}$ and $300 \mu$ of the solution was added to 24 well plates. The plates were incubated for $2 \mathrm{~h}$ at $37^{\circ} \mathrm{C}$, after which they were washed three times with PBS before seeding the cells.

\section{Cell migration in $3 D$ collagen}

Th17 cells were embedded in collagen gels and their motility was evaluated by live cell confocal microscopy. As indicated and before mixing the cells with collagen, $20 \mu \mathrm{g} / \mathrm{ml}$ of recombinant human DDR1:Fc or control human IgG (recombinant Fc fragment) were added to the collagen solution, which was then incubated on a rotary shaker for $2 \mathrm{~h}$ at $4^{\circ} \mathrm{C}$. Th17 cells in medium were labelled with calcein-AM ( $5 \mathrm{nM}$ ) for $30 \mathrm{~min}$ in the dark at $37^{\circ} \mathrm{C}$. After washing with PBS, cell pellets were resuspended in the collagen solution $\left(2 \times 10^{6}\right.$ cells in $\left.300 \mu \mathrm{l}\right)$, distributed in 8 well-Lab-Tek plates and incubated at $37^{\circ} \mathrm{C}$ for $1 \mathrm{~h}$ to allow collagen polymerization. The wells were then placed at $37^{\circ} \mathrm{C}$ in a pre-warmed environmental chamber (LiveCell3, Pathology Devices) and the cells were observed by digital time-lapse using a spinning disk confocal microscope (Wave FX-Borealis-Leica DMI 6000B, Quorum Technologies) and a 10X objective (HC PL Apo NA 0.4). Images were recorded using an Image EM-camera (Hamamatsu photonics) for $30 \mathrm{~min}$ with 30 seconds frame intervals. The migratory distance of 100 cells for each sample was quantified by computer-assisted cell tracking (Volocity software, PerkinElmer) and the average speed (velocity) per cell was calculated and expressed as $\mu \mathrm{m} / \mathrm{min}$.

Th17 cell migration in 3D collagen was also performed using transwell inserts of polycarbonate membrane (3 $\mu \mathrm{m}, \mathrm{BD}$ Biosciences) coated with collagen gels and mounted in 24-well plates. $30 \mu \mathrm{l}$ of the collagen solution was overlaid on the inserts, which were then incubated for $1 \mathrm{~h}$ at $37^{\circ} \mathrm{C}$ to allow collagen polymerization. Cell suspensions $\left(5 \times 10^{5}\right.$ cells in 100 $\mu \mathrm{l}$ of X-vivo medium) were then added on top of the collagen gels. After $24 \mathrm{~h}$, cells that had passed through the transwells to the other side of the filters and in the outer wells, containing or not $1 \mu \mathrm{g} / \mathrm{ml}$ of the chemoattractant CCL20, were recovered and counted microscopically by a blinded observer.

\section{RNA interference}

Human Th17 cells were transfected using the Nucleofector ${ }^{\mathrm{TM}} 2 \mathrm{~b}$ device (program V-024) and the human
T cell Nucleofector kit reagents as recommended by the manufacturer (Lonza technologies, Basel, Switzerland). Cells $\left(5 \times 10^{6}\right)$ cultured for four days in Th17 polarizing conditions were transfected with $200 \mathrm{nM}$ of DDR1 specific siRNAs (HSS1878780) and (HSS187879) or of control non-silencing siRNA (Invitrogen). After nucleofection, the cells were immediately transferred to pre-warmed $\mathrm{X}$-vivo medium and incubated for 6 hours. Live cells were then recovered by Ficoll separation and cultured for an additional 42 hours before being used in subsequent experiments. The efficiency of DDR1 silencing was assessed by flow cytometry and western blot.

\section{Plasmids and cell transfection}

The plasmid encoding the dominant-negative form of MEK-1 (DN-MEK-1) was described in our previous studies $[55,56]$. Human Th17 cells were transfected with $5 \mu \mathrm{g}$ of flag-DN-MEK-1 and control pcDNA plasmids using the nucleofector method as described for siRNA.

\section{ELISA assays for RhoA/ROCK, Rac1 and DDR1 tyrosine phosphorylation}

GTP-bound RhoA and Rac1, and ROCK activity were determined by previously used commercial ELISA kits [57-59]. Th17 cells were activated with immobilized collagen $(100 \mu \mathrm{g} / \mathrm{ml})$ or embedded in collagen gels $(1.65$ $\mathrm{mg} / \mathrm{ml}$ ) for $1 \mathrm{~h}$ at $37^{\circ} \mathrm{C}$. The cells were released from collagen gels by a treatment with collagenase IV (1 mg/ $\mathrm{ml}$ for $30 \mathrm{~min}$ at $37^{\circ} \mathrm{C}$ ). Cells in contact with immobilized collagen (2D) were also treated with collagenase. Equal cell numbers were lysed using RIPA buffer, and equal amounts of proteins for each sample were then assayed for RhoA, Rac1 and ROCK activation as recommended by the manufacturers.

The DDR1 tyrosine kinase activity was measured with the previously used PathScan Phospho-DDR1 (panTyr) Sandwich ELISA kit [60] (Cell Signaling Technology, Beverly, MA) according to the manufacturer's instructions.

\section{Western blot analysis}

DDR1 protein and ERK phosphorylation levels were determined by western blot analysis using antiDDR1 (C20) and anti-phosphorylated ERK1/2 (clone E-4) antibodies as we previously described [54]. The blots were stripped and reprobed with control antibodies.

\section{Air pouch model and Th17 migration in vivo}

All procedures involving animals were conducted according to the requirements of and with the approval of the Laval University animal protection committee. Th17 
recruitment in vivo was carried out as previously described [36]. Briefly, air pouches were raised on the dorsum of 6-8 weeks old female C57BL/6 mice (Jackson Laboratories) by injection of $3 \mathrm{ml}$ sterile filtered air on days 0 and 3 . On day 6,1 ml of PBS containing CCL20 (400 ng) was injected into the pouches to induce Th17 recruitment. Where indicated, $50 \mu \mathrm{g}$ of blocking recombinant mouse receptor DDR1:Fc or control mouse recombinant IgG-Fc (Fc fragment) were injected into the air pouches at the same time as CCL20. 24 h later, mice were sacrificed and air pouches washed twice with cold PBS. The resulting cell suspensions were activated with PMA+ionomycin in the presence of brefeldin A, stained with anti-CD4-FITC $\mathrm{mAb}$, fixed/permeabilized and incubated with rabbit anti-mouse DDR1 (C20) followed with PE-anti-rabbit IgG secondary antibody. The cells were washed, stained with intracellular anti-mouse IL-17-Alexa-647 antibody, washed and analyzed by flow cytometry.

\section{Statistical analysis}

Statistical analysis were performed by the Student's $t$-test. Results with $p<0.05$ were considered significant.

\section{ACKNOWLEDGMENTS}

We acknowledge the bio-imaging platform of the Infectious Disease Research Center at the Centre de Recherche du CHU de Québec for the use of the confocal microscope.

\section{CONFLICTS OF INTEREST}

The authors have no conflict of interest to declare.

\section{GRANT SUPPORT}

This work was supported by grant (290517) from the "Natural Sciences and Engineering Research Council of Canada" to FA. MK holds a scholarship from "Fonds Pierre Borgeat sur les Maladies Rhumatismales de l'Université Laval'.

\section{REFERENCES}

1. Barreiro O, Martin P, Gonzalez-Amaro R and SanchezMadrid F. Molecular cues guiding inflammatory responses. Cardiovasc Res. 2010; 86:174-182.

2. von Andrian UH and Mackay CR. T-cell function and migration. Two sides of the same coin. N Engl J Med. 2000; 343:1020-1034.

3. Dustin ML and de Fougerolles AR. Reprogramming T cells: the role of extracellular matrix in coordination of $\mathrm{T}$ cell activation and migration. Curr Opin Immunol. 2001;
$13: 286-290$.

4. Friedl $\mathrm{P}$ and Weigelin B. Interstitial leukocyte migration and immune function. Nat Immunol. 2008; 9:960-969.

5. Friedl $\mathrm{P}$ and Wolf $\mathrm{K}$. Plasticity of cell migration: a multiscale tuning model. J Cell Biol. 2010; 188:11-19.

6. Korpos E, Wu C, Song J, Hallmann R and Sorokin L. Role of the extracellular matrix in lymphocyte migration. Cell Tissue Res. 2010; 339:47-57.

7. Friedl P, Entschladen F, Conrad C, Niggemann B and Zanker KS. CD4+ T lymphocytes migrating in threedimensional collagen lattices lack focal adhesions and utilize beta1 integrin-independent strategies for polarization, interaction with collagen fibers and locomotion. Eur J Immunol. 1998; 28:2331-2343.

8. Nourshargh S, Hordijk PL and Sixt M. Breaching multiple barriers: leukocyte motility through venular walls and the interstitium. Nat Rev Mol Cell Biol. 2010; 11:366-378.

9. Schmidt $\mathrm{S}$ and Friedl P. Interstitial cell migration: integrindependent and alternative adhesion mechanisms. Cell Tissue Res. 2010; 339:83-92.

10. Lammermann $\mathrm{T}$, Bader BL, Monkley SJ, Worbs $\mathrm{T}$, Wedlich-Soldner R, Hirsch K, Keller M, Forster R, Critchley DR, Fassler R and Sixt M. Rapid leukocyte migration by integrin-independent flowing and squeezing. Nature. 2008; 453:51-55.

11. Leitinger B. Discoidin domain receptor functions in physiological and pathological conditions. Int Rev Cell Mol Biol. 2014; 310:39-87.

12. Vogel WF, Abdulhussein $\mathrm{R}$ and Ford CE. Sensing extracellular matrix: an update on discoidin domain receptor function. Cell Signal. 2006; 18:1108-1116.

13. Valiathan RR, Marco M, Leitinger B, Kleer CG and Fridman R. Discoidin domain receptor tyrosine kinases: new players in cancer progression. Cancer Metastasis Rev. 2012; 31:295-321.

14. Juin A, Di Martino J, Leitinger B, Henriet E, Gary AS, Paysan L, Bomo J, Baffet G, Gauthier-Rouviere C, Rosenbaum J, Moreau V and Saltel F. Discoidin domain receptor 1 controls linear invadosome formation via a Cdc42-Tuba pathway. J Cell Biol. 2014; 207:517-533.

15. Chow CR, Ebine K, Knab LM, Bentrem DJ, Kumar K and Munshi HG. Cancer Cell Invasion in Three-dimensional Collagen Is Regulated Differentially by Galpha13 Protein and Discoidin Domain Receptor 1-Par3 Protein Signaling. J Biol Chem. 2016; 291:1605-1618.

16. Hidalgo-Carcedo C, Hooper S, Chaudhry SI, Williamson P, Harrington K, Leitinger B and Sahai E. Collective cell migration requires suppression of actomyosin at cell-cell contacts mediated by DDR1 and the cell polarity regulators Par3 and Par6. Nat Cell Biol. 2011; 13:49-58.

17. Dang N, Hu J, Liu X, Li X, Ji S, Zhang W, Su J, Lu F, Yang A, Han H, Han W, Jin B and Yao L. CD167 acts as a novel costimulatory receptor in T-cell activation. J Immunother. $2009 ; 32: 773-784$. 
18. Hachehouche LN, Chetoui N and Aoudjit F. Implication of discoidin domain receptor 1 in T cell migration in threedimensional collagen. Mol Immunol. 2010; 47:1866-1869.

19. Kamohara H, Yamashiro S, Galligan C and Yoshimura T. Discoidin domain receptor 1 isoform-a (DDR1alpha) promotes migration of leukocytes in three-dimensional collagen lattices. Faseb J. 2001; 15:2724-2726.

20. McGeachy MJ and McSorley SJ. Microbial-induced Th17: superhero or supervillain? J Immunol. 2012; 189:32853291.

21. Korn T, Bettelli E, Oukka M and Kuchroo VK. IL-17 and Th17 Cells. Annu Rev Immunol. 2009; 27:485-517.

22. Miossec P and Kolls JK. Targeting IL-17 and TH17 cells in chronic inflammation. Nat Rev Drug Discov. 2012; 11:763776.

23. Singh RP, Hasan S, Sharma S, Nagra S, Yamaguchi DT, Wong DT, Hahn BH and Hossain A. Th17 cells in inflammation and autoimmunity. Autoimmun Rev. 2014; 13:1174-1181.

24. Qian X, Chen H, Wu X, Hu L, Huang Q and Jin Y. Interleukin-17 acts as double-edged sword in anti-tumor immunity and tumorigenesis. Cytokine. 2015.

25. Chetoui N, El Azreq MA, Boisvert M, Bergeron ME and Aoudjit F. Discoidin domain receptor 1 expression in activated $\mathrm{T}$ cells is regulated by the ERK MAP kinase signaling pathway. J Cell Biochem. 2011; 112:3666-3674.

26. L'Hote C G, Thomas PH and Ganesan TS. Functional analysis of discoidin domain receptor 1: effect of adhesion on DDR1 phosphorylation. Faseb J. 2002; 16:234-236.

27. Cader FZ, Vockerodt M, Bose S, Nagy E, Brundler MA, Kearns P and Murray PG. The EBV oncogene LMP1 protects lymphoma cells from cell death through the collagen-mediated activation of DDR1. Blood. 2013; 122:4237-4245.

28. Bhatt RS, Tomoda T, Fang Y and Hatten ME. Discoidin domain receptor 1 functions in axon extension of cerebellar granule neurons. Genes Dev. 2000; 14:2216-2228.

29. Kim SH, Lee S, Suk K, Bark H, Jun CD, Kim DK, Choi CH and Yoshimura T. Discoidin domain receptor 1 mediates collagen-induced nitric oxide production in J774A.1 murine macrophages. Free Radic Biol Med. 2007; 42:343-352.

30. Afonso PV, McCann CP, Kapnick SM and Parent CA. Discoidin domain receptor 2 regulates neutrophil chemotaxis in 3D collagen matrices. Blood. 2013; 121:1644-1650.

31. Wolf K, Muller R, Borgmann S, Brocker EB and Friedl P. Amoeboid shape change and contact guidance: T-lymphocyte crawling through fibrillar collagen is independent of matrix remodeling by MMPs and other proteases. Blood. 2003; 102:3262-3269.

32. Acosta-Rodriguez EV, Rivino L, Geginat J, Jarrossay D, Gattorno M, Lanzavecchia A, Sallusto F and Napolitani G. Surface phenotype and antigenic specificity of human interleukin 17-producing $\mathrm{T}$ helper memory cells. Nat
Immunol. 2007; 8:639-646.

33. Hirota K, Yoshitomi H, Hashimoto M, Maeda S, Teradaira S, Sugimoto N, Yamaguchi T, Nomura T, Ito H, Nakamura T, Sakaguchi N and Sakaguchi S. Preferential recruitment of CCR6-expressing Th17 cells to inflamed joints via CCL20 in rheumatoid arthritis and its animal model. J Exp Med. 2007; 204:2803-2812.

34. Wang C, Kang SG, Lee J, Sun Z and Kim CH. The roles of CCR6 in migration of Th17 cells and regulation of effector T-cell balance in the gut. Mucosal Immunol. 2009; 2:173183.

35. Webb A, Johnson A, Fortunato M, Platt A, Crabbe T, Christie MI, Watt GF, Ward SG and Jopling LA. Evidence for PI-3K-dependent migration of Th17-polarized cells in response to CCR2 and CCR6 agonists. J Leukoc Biol. 2008; 84:1202-1212.

36. Alcaide P, Maganto-Garcia E, Newton G, Travers R, Croce KJ, Bu DX, Luscinskas FW and Lichtman AH. Difference in Th1 and Th17 lymphocyte adhesion to endothelium. J Immunol. 2012; 188:1421-1430.

37. Paulissen SM, van Hamburg JP, Dankers W and Lubberts E. The role and modulation of CCR6 + Th17 cell populations in rheumatoid arthritis. Cytokine. 2015; 74:43-53.

38. Sahai E and Marshall CJ. Differing modes of tumour cell invasion have distinct requirements for Rho/ROCK signalling and extracellular proteolysis. Nat Cell Biol. 2003; 5:711-719.

39. Sanz-Moreno V, Gadea G, Ahn J, Paterson H, Marra P, Pinner S, Sahai E and Marshall CJ. Rac activation and inactivation control plasticity of tumor cell movement. Cell. 2008; 135:510-523.

40. Ram R, Lorente G, Nikolich K, Urfer R, Foehr E and Nagavarapu U. Discoidin domain receptor-1a (DDR1a) promotes glioma cell invasion and adhesion in association with matrix metalloproteinase-2. J Neurooncol. 2006; 76:239-248.

41. Song S, Shackel NA, Wang XM, Ajami K, McCaughan GW and Gorrell MD. Discoidin domain receptor 1: isoform expression and potential functions in cirrhotic human liver. Am J Pathol. 2011; 178:1134-1144.

42. Yoshida D and Teramoto A. Enhancement of pituitary adenoma cell invasion and adhesion is mediated by discoidin domain receptor-1. J Neurooncol. 2007; 82:29-40.

43. Yeh YC, Wang $\mathrm{CZ}$ and Tang MJ. Discoidin domain receptor 1 activation suppresses alpha2betal integrindependent cell spreading through inhibition of $\mathrm{Cdc} 42$ activity. J Cell Physiol. 2009; 218:146-156.

44. Huang Y, Arora P, McCulloch CA and Vogel WF. The collagen receptor DDR1 regulates cell spreading and motility by associating with myosin IIA. J Cell Sci. 2009; 122:1637-1646.

45. Xu H, Bihan D, Chang F, Huang PH, Farndale RW and Leitinger B. Discoidin domain receptors promote alpha1beta1- and alpha2beta1-integrin mediated cell 
adhesion to collagen by enhancing integrin activation. PLoS One. 2012; 7:e52209.

46. Friedl P. Prespecification and plasticity: shifting mechanisms of cell migration. Curr Opin Cell Biol. 2004; 16:14-23.

47. Lammermann $\mathrm{T}$ and Germain $\mathrm{RN}$. The multiple faces of leukocyte interstitial migration. Semin Immunopathol. 2014; 36:227-251.

48. Lammermann $\mathrm{T}$ and Sixt $\mathrm{M}$. Mechanical modes of 'amoeboid' cell migration. Curr Opin Cell Biol. 2009; 21:636-644.

49. Tong J, Li L, Ballermann B and Wang Z. Phosphorylation and Activation of RhoA by ERK in Response to Epidermal Growth Factor Stimulation. PLoS One. 2016; 11:e0147103.

50. Bist P, Phua QH, Shu S, Yi Y, Anbalagan D, Lee LH, Sethi G, Low BC and Lim LH. Annexin-A1 controls an ERKRhoA-NFkappaB activation loop in breast cancer cells. Biochem Biophys Res Commun. 2015; 461:47-53.

51. Jo M, Thomas KS, Somlyo AV, Somlyo AP and Gonias SL. Cooperativity between the Ras-ERK and Rho-Rho kinase pathways in urokinase-type plasminogen activatorstimulated cell migration. J Biol Chem. 2002; 277:1247912485 .

52. Manel N, Unutmaz D and Littman DR. The differentiation of human $\mathrm{T}(\mathrm{H})-17$ cells requires transforming growth factor-beta and induction of the nuclear receptor RORgammat. Nat Immunol. 2008; 9:641-649.

53. Li SS, Forslow A and Sundqvist KG. Autocrine regulation of $\mathrm{T}$ cell motility by calreticulin-thrombospondin-1 interaction. J Immunol. 2005; 174:654-661.

54. El Azreq MA, Arseneault C, Boisvert M, Page N, Allaeys I, Poubelle PE, Tessier PA and Aoudjit F. Cooperation between IL-7 Receptor and Integrin alpha2beta1 (CD49b) Drives Th17-Mediated Bone Loss. J Immunol. 2015; 195:4198-4209.
55. El Azreq MA, Naci D and Aoudjit F. Collagen/beta1 integrin signaling up-regulates the ABCC1/MRP-1 transporter in an ERK/MAPK-dependent manner. Mol Biol Cell. 2012; 23:3473-3484.

56. Naci D, El Azreq MA, Chetoui N, Lauden L, Sigaux F, Charron D, Al-Daccak R and Aoudjit F. alpha2beta1 integrin promotes chemoresistance against doxorubicin in cancer cells through extracellular signal-regulated kinase (ERK). J Biol Chem. 2012; 287:17065-17076.

57. Zhang Z, Yang M, Chen R, Su W, Li P, Chen S, Chen $\mathrm{Z}$, Chen $\mathrm{A}$, Li S and Hu C. IBP regulates epithelial-tomesenchymal transition and the motility of breast cancer cells via Rac1, RhoA and Cdc42 signaling pathways. Oncogene. 2015; 33:3374-3382.

58. Xu Y, Li J, Ferguson GD, Mercurio F, Khambatta G, Morrison L, Lopez-Girona A, Corral LG, Webb DR, Bennett $\mathrm{BL}$ and $\mathrm{Xie} \mathrm{W}$. Immunomodulatory drugs reorganize cytoskeleton by modulating Rho GTPases. Blood. 2009; 114:338-345.

59. Zhang W, Huang Y and Gunst SJ. The small GTPase RhoA regulates the contraction of smooth muscle tissues by catalyzing the assembly of cytoskeletal signaling complexes at membrane adhesion sites. J Biol Chem. 2012; 287:3399634008.

60. Favreau AJ, Vary CP, Brooks PC and Sathyanarayana P. Cryptic collagen IV promotes cell migration and adhesion in myeloid leukemia. Cancer Med. 2014; 3:265-272. 